\title{
Thomas Bauermann
}

\section{Der Anknüpfungsgegenstand im europäischen Internationalen Lauterkeitsrecht}

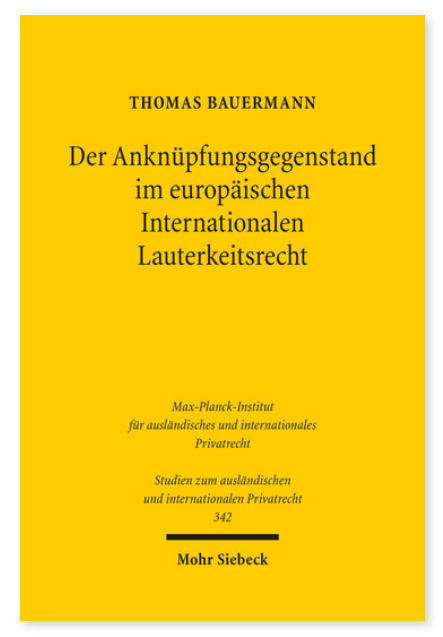

2015. XXVI, 332 Seiten. StudIPR 342

SBN 978-3-16-153947-3

eBook PDF $89,00 €$

ISBN 978-3-16-153908-4

fadengeheftete Broschur $89,00 €$
Artikel 6 Abs. 1-2 Rom II-Verordnung enthält erstmals einheitliche europäische Kollisionsnormen für außervertragliche Schuldverhältnisse aus unlauterem Wettbewerbsverhalten. Untersucht wird das europäisch-autonome Verständnis dieses Anknüpfungsgegenstands, dessen Auslegung aufgrund großer Unterschiede im Lauterkeitsrecht der Mitgliedstaaten besondere Probleme aufwirft. Nach Klärung des maßgeblichen Verständnisses der Anknüpfungspunkte analysiert Thomas Bauermann, insbesondere unter Berücksichtigung des unionsrechtlichen Kontextes und der Ergebnisse der Rechtsvergleichung, ausführlich die Merkmale des Wettbewerbsverhaltens und der Unlauterkeit. Zentrale Bedeutung wird der Schutzrichtung lauterkeitsrechtlicher Sachnormen beigemessen, wobei die Schutzzwecke von Verhaltensnormen einerseits und Sanktionsnormen andererseits eingehend betrachtet werden. Auch die Abgrenzung zu anderen Anknüpfungsgegenständen wird umfassend erörtert.

Thomas Bauermann Geboren 1984; Studium der Rechtswissenschaft an der WWU Münster und der Universitat de Barcelona; wissenschaftliche Hilfskraft bzw. wissenschaftlicher Mitarbeiter am Institut für Internationales Wirtschaftsrecht, Lehrstuhl für Internationales Privatrecht und Bürgerliches Recht, der WWU Münster; LL.M.-Studium »Versicherungsrecht« in Münster; 2014 Promotion; seit August 2013 Rechtsreferendar des Landes Nordrhein-Westfalen.

Jetzt bestellen:

https://mohrsiebeck.com/buch/der-anknuepfungsgegenstand-im-europaeischen-internationalen-lauterkeitsrecht9783161539473?no_cache=1

order@mohrsiebeck.com

Telefon: +49 (0)7071-923-17

Telefax: $+49(0) 7071-51104$ 